\title{
A comprehensive proteogenomic study of the human Brucella vaccine strain $104 \mathrm{M}$
}

\author{
Xiaodong Zai, Qiaoling Yang, Kun Liu, Ruihua Li, Mengying Qian, Taoran Zhao, Yaohui Li, Ying Yin, Dayong Dong, \\ Ling Fu, Shanhu Li, Junjie Xu* and Wei Chen ${ }^{*}$
}

\begin{abstract}
Background: Brucella spp. are Gram-negative, facultative intracellular pathogens that cause brucellosis in both humans and animals. The $B$. abortus vaccine strain $104 \mathrm{M}$ is the only vaccine available in China for the prevention of brucellosis in humans. Although the B. abortus $104 \mathrm{M}$ genome has been fully sequenced, the current genome annotations are not yet complete. In addition, the main mechanisms underpinning its residual toxicity and vaccineinduced immune protection have yet to be elucidated. Mapping the proteome of B. abortus $104 \mathrm{M}$ will help to improve genome annotation quality, thereby facilitating a greater understanding of its biology.

Results: In this study, we utilized a proteogenomic approach that combined subcellular fractionation and peptide fractionation to perform a whole-proteome analysis and genome reannotation of $B$. abortus $104 \mathrm{M}$ using highresolution mass spectrometry. In total, 1,729 proteins (56.3\% of 3,072) including 218 hypothetical proteins were identified using the culture conditions that were employed this study. The annotations of the B. abortus $104 \mathrm{M}$ genome were also refined following identification and validation by reverse transcription-PCR. In addition, 14 pivotal virulence factors and 17 known protective antigens known to be involved in residual toxicity and immune protection were confirmed at the protein level following induction by the $104 \mathrm{M}$ vaccine. Moreover, a further insight into the cell biology of multichromosomal bacteria was obtained following the elucidation of differences in protein expression levels between the small and large chromosomes.
\end{abstract}

Conclusions: The work presented in this report used a proteogenomic approach to perform whole-proteome analysis and genome reannotation in B. abortus $104 \mathrm{M}$; this work helped to improve genome annotation quality. Our analysis of virulence factors, protective antigens and other protein effectors provided the basis for further research to elucidate the mechanisms of residual toxicity and immune protection induced by the $104 \mathrm{M}$ vaccine. Finally, the potential link between replication dynamics, gene function, and protein expression levels in this multichromosomal bacterium was detailed.

Keywords: Brucella abortus 104 M, Proteogenomic, Genome reannotation, Virulence factor, Protective antigen, Multichromosomal bacteria

\section{Background}

Brucella spp. are Gram-negative, intracellular bacterial pathogens that can cause brucellosis in both humans and animals [1]. As one of the most common zoonotic diseases, brucellosis is a significant economic and public health problem worldwide with more than 500,000 new cases reported annually [2]. B. abortus, B. melitensis, and $B$. suis are the most pathogenic strains in humans and

\footnotetext{
* Correspondence: xujunjie@sina.com; cw0226@foxmail.com Laboratory of Vaccine and Antibody Engineering, Beijing Institute of Biotechnology, Beijing, China
}

have been identified as potential bio-terrorism agents [3]. At present, vaccination is the most effective approach for preventing and controlling brucellosis $[4,5]$. The $B$. abortus $104 \mathrm{M}$ vaccine strain is the only vaccine that has been widely used in China for the control and prevention of human brucellosis since its approval by the Chinese Food and Drug Administration in 1965 [6]. This vaccine strain was isolated from the placenta of a sick cow in a former Soviet republic. The strain exhibits strong immunogenicity with low and stable residual toxicity in experimental animals [7]. 
Although the $B$. abortus $104 \mathrm{M}$ genome has been fully sequenced (CP009625-CP009626), it was annotated using in silico methods with many unannotated genes and errors. Furthermore, a large number of hypothetical proteins $(620$ of 3,072) have yet to be annotated, thereby limiting our understanding of the biological processes pertaining to this strain [7]. Proteogenomics is an important tool for integrating protein-level information into the genome annotation process, thereby greatly improving genome annotation quality [8]. Therefore, a proteogenomics study is required to both validate the $B$. abortus $104 \mathrm{M}$ genome annotation and re-annotate mis-annotated novel genes.

The underlying molecular and physiological mechanisms that cause possible residual toxicity and immune protection following $104 \mathrm{M}$ vaccine induction remain to be elucidated. In our preliminary work, we have determined the whole-genome sequence of $104 \mathrm{M}$ and conducted a comparative analysis against its homologous virulent strain A13334 [7]. It revealed highly similar genome structures but a set of genes missing between $104 \mathrm{M}$ and A13334 that related to virulence alteration. This observation suggests that the remaining virulence associated genes in the $104 \mathrm{M}$ genome may lead to the residual toxicity associated with the $104 \mathrm{M}$ vaccine. We also observed a number of protective antigens that can promote both humoral and cellular immunity in the 104 $\mathrm{M}$ genome. The occurrence of these antigens is likely to result in the enhancement of host defense mechanisms pertaining to bacterial infections. The identification of these pivotal virulence factors and protective antigens at the protein level is likely to be beneficial in the elucidation of mechanisms that underpin residual toxicity and immune protection following induction by the $104 \mathrm{M}$ vaccine.

To this end, we used a proteogenomics approach that combined subcellular fractionation and peptide fractionation to perform whole-proteome analysis and genome reannotation in $B$. abortus $104 \mathrm{M}$. Virulence factors, known protective antigens and other protein effectors that are critical for bacterial virulence and vaccine protection were identified at the protein level. Moreover, differences in protein expression levels between the small and large chromosomes in this multichromosomal bacterium were analyzed. This study presents a comprehensive $B$. abortus $104 \mathrm{M}$ proteome analysis while also providing a platform to aid in the understanding of the molecular mechanisms pertaining to the $104 \mathrm{M}$ vaccine.

\section{Results and discussion}

Proteogenomic strategy for the analysis of B. abortus $104 \mathrm{M}$ This study incorporated a genome-wide protein identification survey of B. abortus $104 \mathrm{M}$ using in vitro culture conditions, thereby facilitating refinement of previous genome annotations. Traditional approaches to proteomics analyses of $B$. abortus based on two dimensional gel electrophoresis (2-DE) and high performance liquid chromatography (HPLC) coupled with mass spectrometry (MS) have proved successful; however, hydrophobic and low abundance proteins are under-represented using this approach [9-14]. To enhance coverage of the expressed genome, different strategies for subcellular and peptide fractionation were combined with subsequent LC-tandem mass spectrometry (MS/MS) analysis to resolve $B$. abortus proteins for global analysis [15]. In the present study, we performed subcellular fractionation prior to protein extraction to reduce interference. Whole cell protein and membrane protein extracts were prepared for strain $104 \mathrm{M}$. Peptide fractionation prior to analysis is an alternative method that achieves higher proteome coverage. Complexity reduction was achieved by SDSpolyacrylamide gel electrophoresis (PAGE) and strong cation exchange (SCX) HPLC separation [16].

In total, 90 samples were generated and subjected to LC-MS/MS analysis using a linear trap quadrupole (LTQ) Obitrap Velos mass spectrometer. The workflow of this study is summarized in Fig. 1. The raw MS data were searched against two databases: (i) a UniProt protein database (UP000064067) and (ii) a 6 F translated genome database of B. abortus 104 M (Additional file 1: Table S1) [17]. The search was conducted using SearchGUI and required four different search algorithms (X!Tandem, MS-GF+, Comet and PeptideShaker). Peptides and proteins were inferred from the spectrum identification results using PeptideShaker. Peptide spectrum matches (PSMs), peptides and proteins were validated at a $1.0 \%$ false discovery rate (FDR) threshold estimated using the decoy hit distribution (Additional file 1: Table S2-S4). The distribution of precursor mass deviations and the identified peptides that were observed following MS analysis are presented in Additional file 2: Figure S1.

\section{Analysis of $B$. abortus 104 M protein expression}

We mapped the unique peptides identified in this study to the B. abortus $104 \mathrm{M}$ UniProt database (3,072 proteins), and only proteins that were identified by at least two unique peptides were confirmed. A total of 1,729 proteins $(1,224$ proteins encoded by chromosome 1 and 505 encoded by chromosome 2) were identified, covering approximately $56.3 \%$ of the predicted proteome (Fig. 2, Additional file 1: Table S2). Approximately 85.1\% $(2.79 \mathrm{Mb})$ of the Brucella genome is protein-coding with annotations in the $104 \mathrm{M}$ database, and the expressed genome corresponded to $63.8 \%(1.78 \mathrm{Mb})$ of the annotated protein-coding regions. Each identified protein was represented with an average sequence coverage of $34.9 \%$ (Additional file 2: Figure S1).

The proteins were identified following in-gel fractionation (SDS-PAGE), in-solution fractionation (SCX), whole 


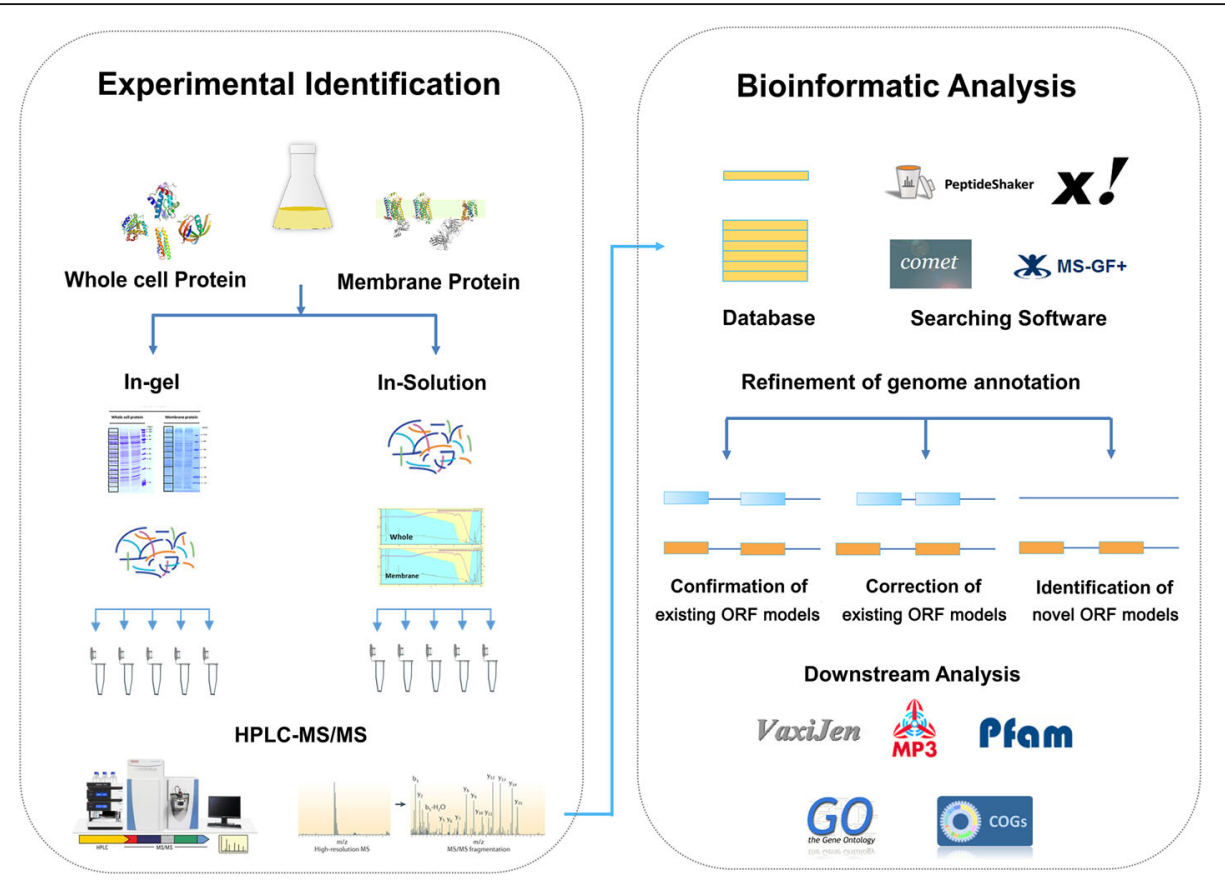

Fig. 1 Experimental identification and bioinformatics analysis workflow of the proteogenomics study. Whole cell protein and membrane protein extracts were prepared from B. abortus $104 \mathrm{M}$ cultures grown to exponential phase. Complexity reduction was achieved by SDS-PAGE and SCX HPLC separation. After protein extraction and pre-fractionation, enzymatically digested proteins or peptides were analyzed by LC-MS/MS. All spectra were searched against the six-frame (6 F) database and the UniProt database by SearchGUI. Identified peptides were mapped to the $104 \mathrm{M}$ genome and annotation was refined at three levels: (i) confirmation of the existing open reading frame (ORF) models; (ii) refinement of the existing ORF models; and (iii) identification of novel ORF models. Subsequently, the protein physicallchemical property and function were analyzed

cell protein fractionation and membrane protein fractionation (Fig. 2b). Many of the proteins that were uniquely identified in the membrane fractions had relatively extreme grand average of hydropathy (GRAVY) scores (Additional file 2: Figure S2). Large proteins were more likely to be identified after SCX separation than by SDS-PAGE and approximately all unique proteins with molecular weights (MWs) greater than $90 \mathrm{kDa}$ were identified by SCX (Additional file 2: Figure S2). This further emphasizes the advantage of membrane fractionation and SCX for protein separation. Lamontagne et al. identified 621 proteins in preliminary work using three protein separation approaches: SDS-PAGE, isoelectric focusing, and off-line 2-D peptide chromatography [11]. In this study, a combination of subcellular fractionation and peptide fractionation increased the number of membrane and cytoplasmic proteins identifiable by mass spectrometry; This approach provided a significantly higher degree of discrimination and enhanced coverage of the expressed genome.

\section{Physical and chemical property distributions of identified proteins}

The proteins identified in this study covered a wide range of MW and isoelectric point (pI) values (Fig. 3a) [18]. The theoretical MW distribution for the identified proteins ranged from $4.7 \mathrm{kDa}$ (Entericidin EcnAB protein) to $320.4 \mathrm{kDa}(\mathrm{NdvB}$ protein). Moreover, approximately $85.0 \%(1,469$ of 1,729$)$ of all the identified proteins had MWs in the range $10-60 \mathrm{kDa}$ (Fig. 3b). The $\mathrm{pI}$ values of the identified proteins ranged from 3.67 to 11.88 . These values are similar to those observed for the total proteome (Fig. 3c). Approximately $67.0 \%$ of the proteins identified in the $104 \mathrm{M}$ database had $\mathrm{pI}$ values between 6 and 8. Eleven proteins with high pI scores $(\geq 11)$ and 20 with high MW $(\geq 120 \mathrm{kDa})$ were beyond the general separation limits of 2-DE.

The GRAVY values for all of the identifications (average -0.012 ) were used to evaluate protein hydrophilicity and hydrophobicity (Fig. 3d). A total of 58 proteins were identified with high GRAVY scores $(\geq 0.6)$; such proteins are so hydrophobic that they are rarely detected by $2-\mathrm{DE}$ due to their susceptibility to precipitation during isoelectric focusing. A total of 301 potential membrane proteins with at least one transmembrane helix (TMH) were identified (Fig. 3e) [19]. Among these, the number of predicted TMHs ranged from one to 25. The subcellular localization of identified proteins was predicted using Cello2.5 (Fig. 3f) [20]. Two hundred and eightythree proteins $(16.4 \%)$ were predicted to be localized to the cytoplasmic membrane and 1,007 (58.2\%) of the proteins were identified as cytoplasmic, which is consistent 

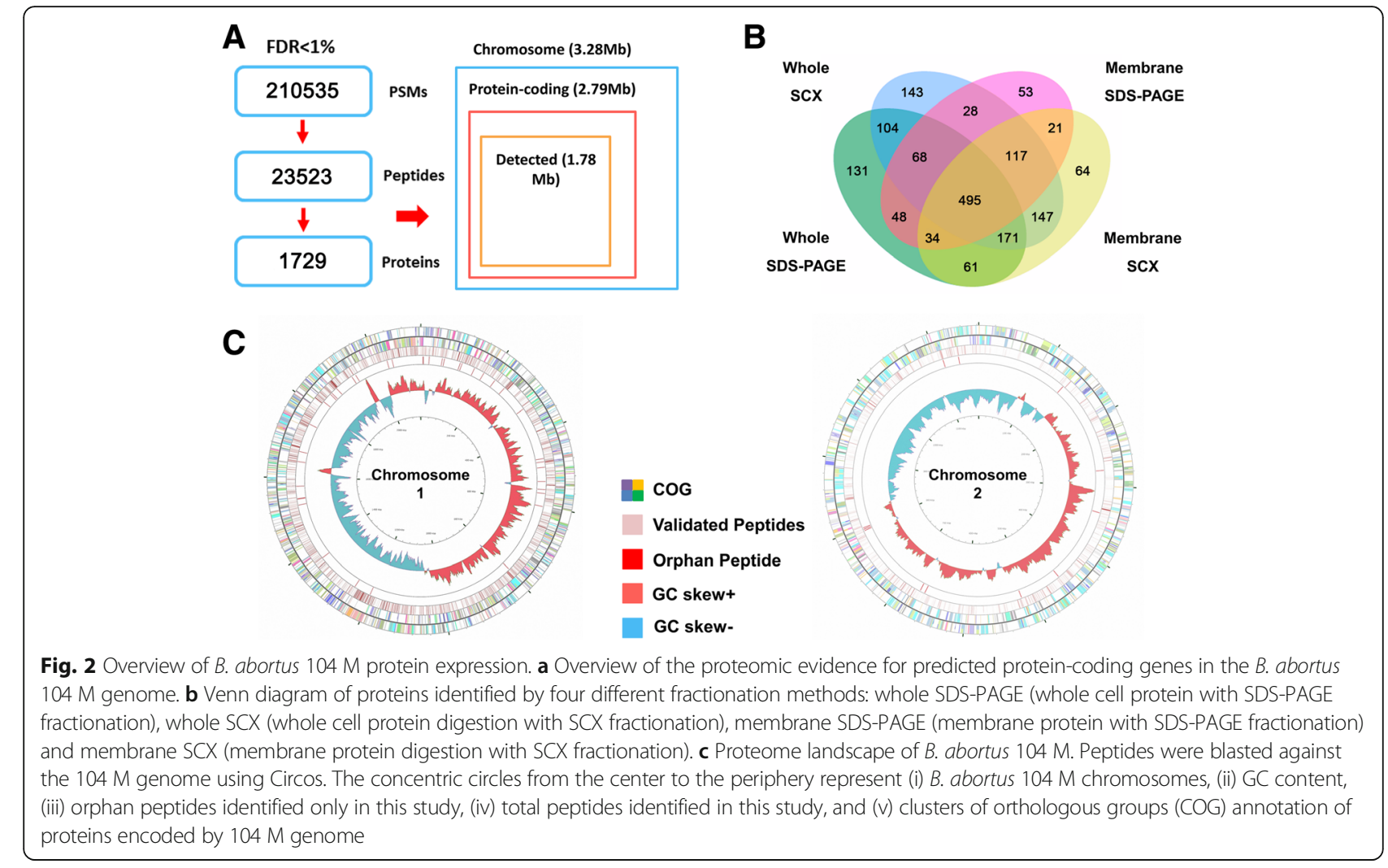

with findings from previous studies [11]. Each identified protein was classified based on clusters of orthologous groups (COG) and associated with a functional category (Fig. 3g) [21]. Among the 1,729 identified proteins, 1,570 were annotated in the COG database. Many of the identified proteins were involved in amino acid transport and metabolism, translation, ribosomal structure and biogenesis, energy production and energy conversion. All of these categories contain key functional proteins that are important for cell growth and reproduction.

\section{Identification of virulence factors and function analysis}

Brucella is unusual because it does not harbor typical virulence factors. Instead, its virulence appears to be an integrated aspect of its physiology, exhibiting a tendency to invade and persist in the human host through inhibition of programmed cell death [22, 23]. As previously stated, the genomic analysis of B. abortus $104 \mathrm{M}$ revealed the presence of some virulence associated genes in the $104 \mathrm{M}$ genome which may be related to the vaccine residual toxicity. In this study, we confirmed the presence of $104 \mathrm{M}$-specific virulence factors of $104 \mathrm{M}$ at the protein level following cell culture. The majority of these factors were observed to be involved in intracellular survival, two-component regulatory systems, and the VirB secretion or transport system (Table 1) [24]. For example, Brucella cyclic $\beta$-1,2-glucan $(C \beta G)$ is a key virulence factor that interferes with the maturation of the Brucella-containing vacuole and consequently, prevents its fusion with lysosomes [25]. The enzyme responsible for the synthesis of C $\beta G$ (Cyclic $\beta$-1,2-glucan synthase protein, Cgs) was represented by 54 peptides. Similarly, the WbkA and $\mathrm{WbkC}$ proteins, which were represented by six and 14 peptides, respectively, are involved in the synthesis of the O-polysaccharide and its translocation to the periplasm [26]. In addition, the BvrR/BvrS sensory-regulatory system, which plays an important role in the stealth program, was represented by 23 and eight peptides, respectively [27]. Moreover, T4SS, which is encoded by the Virb operon (Virb8, represented by three peptides), is also a vitally important factor used for the translocation of virulence factors into mammalian cells and is required for Brucella trafficking diversion [28]. Finally, in total 14 pivotal virulence factors in $104 \mathrm{M}$ were identified at the protein level following cell culture. We speculate that the identification of these factors will help us to elucidate the mechanisms that underpin residual toxicity pertaining to the 104 $\mathrm{M}$ vaccine.

\section{Identification of known protective antigens and function analysis}

The efficacy of the $104 \mathrm{M}$ vaccine against brucellosis has been largely confirmed following its widespread application 

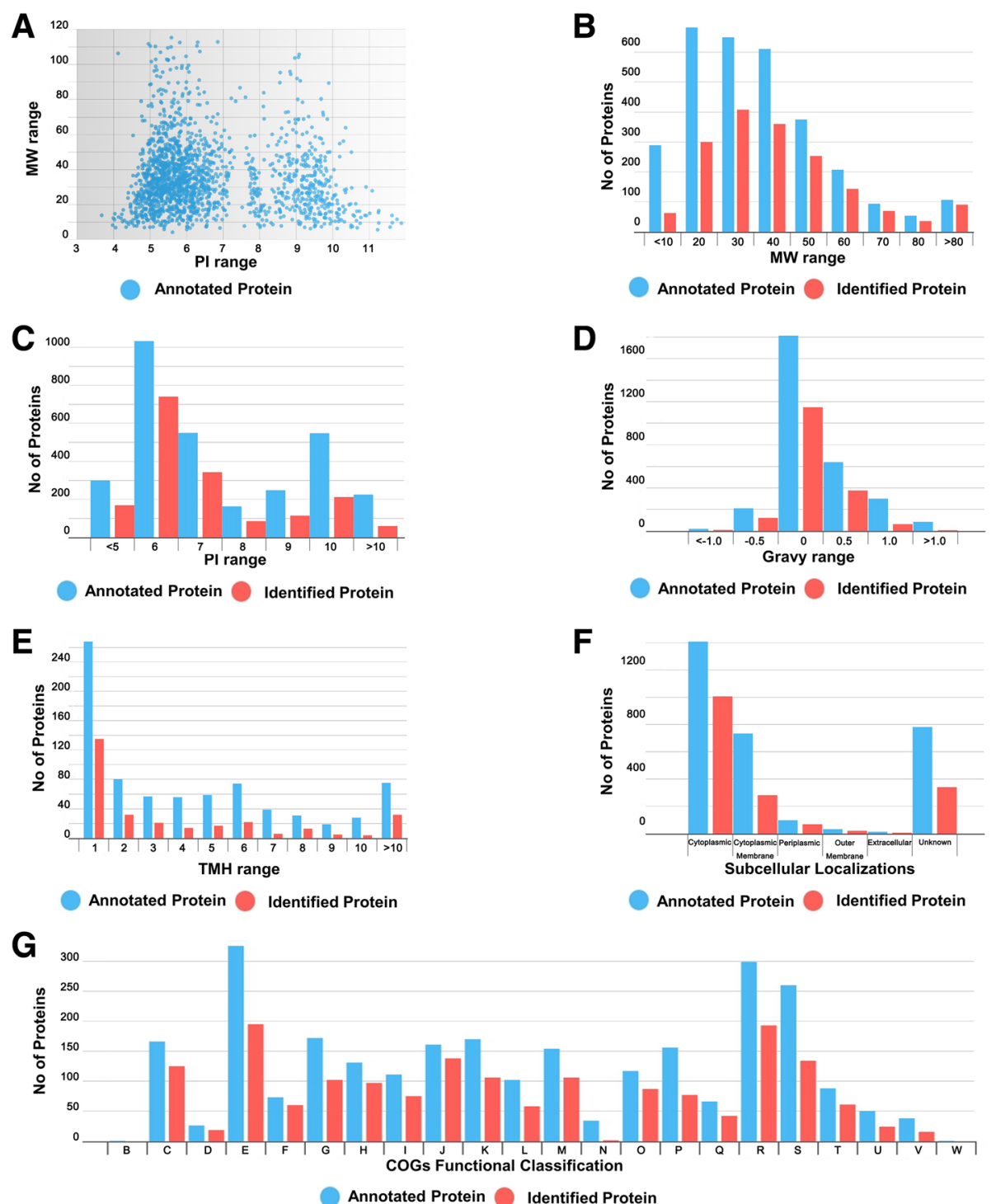

Fig. 3 Distribution of the predicted and identified proteins in the B. abortus $104 \mathrm{M}$ genome according to their molecular function. a Distribution of pl values and MW ranges. Distribution of identified protein $\mathbf{b} \mathrm{MW}, \mathbf{c}$ pl, $\mathbf{d}$ GRAV, e TMH, $\mathbf{f}$ subcellular localization and $\mathbf{g}$ functional classification of proteins identified according to clusters of orthologous groups (COGs). Annotated and identified proteins are shown in blue and red, respectively

in China; however, the predominant protective mechanisms associated with the vaccine remain to be elucidated. Interestingly, almost all of the widely reported putative Brucella protective antigens listed in the Protegen database were observed to harbor high peptide numbers (Table 1) [29, 30]. For example, 110 peptides derived from the molecular chaperone, DnaK, were identified. This is a member of the highly conserved 70-kDa heat-shock protein (hsp70) family, which assists in folding nascent polypeptide chains and is a known protective antigen [31]. In addition, 37 peptides were identified to be derived from the L7/L12 ribosomal protein, which is a major constituent of the Brucella nucleoprotein fraction used in Brucella skin tests as a vaccine candidate [32]. Moreover, the outer membrane proteins of $B$. abortus, including the Omp16, Omp19, and Omp25 potential immunogenic antigens, which have been widely explored as subunit vaccines, were represented by 17,13 , and 22 peptides, respectively [33]. Similarly, 54 peptides derived from the antigen periplasmic binding protein P39 were reported. The latter has been reported to be a T-cell immunodominant Brucella antigen that induces a Th1-type immune response [34]. Furthermore, peptides derived from other confirmed or putative protective antigens that induce different levels of protective immunity and cellular 
Table 1 The virulence factors and known protective antigens of B. abortus $104 \mathrm{M}$ identified in this study

\begin{tabular}{|c|c|c|c|c|c|}
\hline Function Group & Protein Accessions & Name & Description & Protein Length & Identified Peptides \\
\hline \multirow{14}{*}{ Virulence factors } & A0A0M5MHD4 & Cgs & Cyclic $\beta-1,2-$ glucan synthase & 2867 & 135 \\
\hline & AOAOM4TBIO & Gmd & GDP-mannose 4,6-dehydratase & 362 & 46 \\
\hline & $\mathrm{AOA0M4SH46}$ & Pgm & Phosphoglucomutase & 543 & 36 \\
\hline & A0A0M3UZI1 & BvrR & Transcriptional regulator & 239 & 23 \\
\hline & A0A0M5MBG4 & Per & Perosamine synthetase & 367 & 19 \\
\hline & A0A0M3UYN6 & Wzt & Teichoic acid ABC transporter ATPase & 252 & 16 \\
\hline & A0A0M4SAL4 & WbkC & GDP-mannose 4,6-dehydratase & 259 & 14 \\
\hline & A0A0M4TBJ0 & ManAoAg & Mannose-6-phosphate isomerase & 390 & 11 \\
\hline & A0A0M5MBI2 & ManCoAg & Mannose-1-phosphate guanyltransferase & 474 & 10 \\
\hline & A0A0M5MCJ0 & BvrS & Histidine kinase & 601 & 8 \\
\hline & A0A0M4S2A5 & WbkA & Glycosyl transferase family & 372 & 6 \\
\hline & A0A0M5MH13 & RicA & Acetyltransferase & 175 & 5 \\
\hline & A0A0M4TDU8 & VirB8 & Conjugal transfer protein & 239 & 3 \\
\hline & A0A0M4SA70 & BtpA & Molecular chaperone & 275 & 2 \\
\hline \multirow[t]{17}{*}{ Protective antigens } & A0A0M4SJF6 & Dnak & Molecular chaperone DnaK & 637 & 110 \\
\hline & A0A0M4TBF8 & & Trigger factor & 485 & 77 \\
\hline & A0A0M5MBQ0 & CobB & Cobyrinic acid a,c-diamide synthase & 436 & 15 \\
\hline & A0A0M4TD92 & GapA & Glyceraldehyde-3-phosphate dehydrogenase & 335 & 81 \\
\hline & A0A0M4SOA3 & SurA & Molecular chaperone SurA & 318 & 17 \\
\hline & A0A0M4S1G5 & OmpA & Membrane protein & 261 & 13 \\
\hline & A0A0M4SJ84 & Bp26 & Membrane protein & 250 & 9 \\
\hline & AOAOM4SZK3 & Omp25 & Membrane protein & 213 & 22 \\
\hline & AOAOM4SCZO & DnaJ & Molecular chaperone DnaJ & 377 & 20 \\
\hline & A0A0M4S9R8 & SodC & Superoxide dismutase & 173 & 47 \\
\hline & A0A0M3UYK8 & & Invasion protein & 173 & 32 \\
\hline & A0A0M4SDF8 & Omp19 & Membrane protein & 177 & 13 \\
\hline & A0A0M4TD78 & Omp16 & Membrane protein & 168 & 17 \\
\hline & A0A0M3V026 & Ferritin & Bacterioferritin & 161 & 9 \\
\hline & А0A0M4T393 & RibE & Riboflavin synthase subunit beta & 158 & 11 \\
\hline & A0A0M4TCK8 & $\mathrm{L} 7 / \mathrm{L} 12$ & $50 \mathrm{~S}$ ribosomal protein & 124 & 38 \\
\hline & A0A0M4SID4 & AsnC & ArsR family transcriptional regulator & 159 & 25 \\
\hline
\end{tabular}

immune responses against brucellosis, such as trigger factor $(\mathrm{TF})$ chaperone protein, $\mathrm{Cu}-\mathrm{Zn}$ superoxide dismutase (SOD) proteins, and the transcriptional regulatory proteins AsnC, were also identified in this study [5, 30, 35]. Taken together, our results indicate that B. abortus $104 \mathrm{M}$ expresses 17 known protective antigens under in vitro culture conditions. These antigens could promote both humoral and cellular immunity, resulting in the enhancement of host defense mechanisms pertaining to subsequent bacterial infections. Our analysis of protective antigens provides the basis for further research to elucidate the mechanisms of immune protection induced by the $104 \mathrm{M}$ vaccine.

\section{Identification of hypothetical proteins and function analysis}

Since a large number of hypothetical proteins (620 of 3,072 ) remain to be annotated, our understanding of the biological processes associated with this strain is limited. In this study, 218 hypothetical proteins were identified in the proteomics analysis of 104 M (Additional file 1: Table S5). Among these, 69 hypothetical proteins were allocated gene ontology (GO) terms as assigned by Blast2GO (Fig. 4a) [36]. Many of the identified hypothetical proteins were involved in cellular metabolic process with catalytic activity. In addition, 25 of the hypothetical proteins (with scores higher than the 

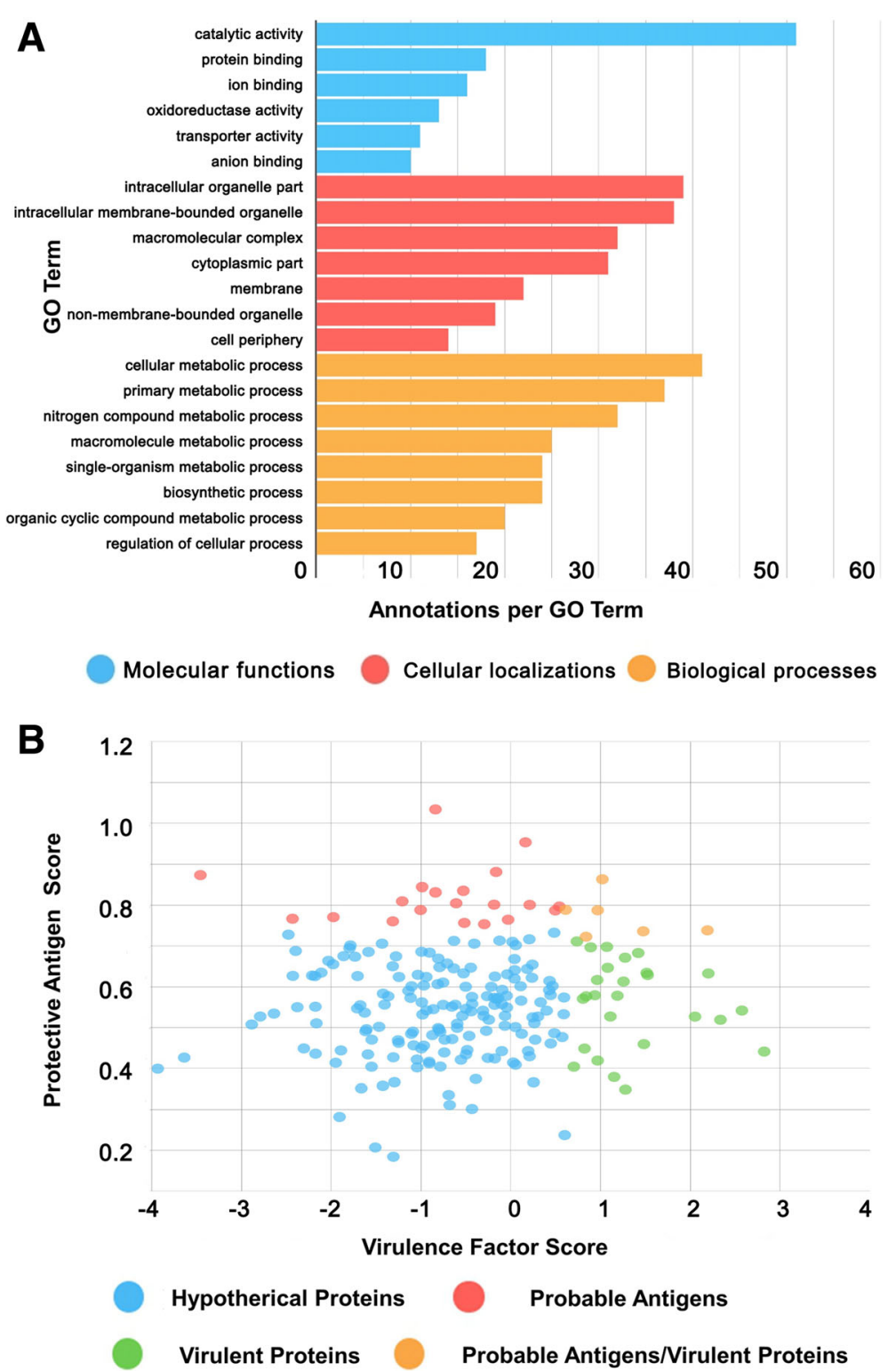

Fig. 4 Function analysis of the hypothetical proteins identified in B. abortus 104 M. a Biological processes, molecular functions, and cellular localizations of all identified hypothetical proteins with GO terms as assigned by Blast2GO. b Distribution of the main "Probable Antigens" and "Virulent Proteins" among the identified hypothetical proteins

threshold of 0.7) were identified as "probable antigens" following alignment-independent prediction by the VaxiJen server [37]. Thirty-two of the hypothetical proteins (with scores higher than the threshold of 0.6) were identified as "virulent proteins" by the MP3 tool [38]. Distribution of the main "probable antigens" and "virulent proteins" among the hypothetical proteins are shown in Fig. 4b. Twenty-one unique peptides were mapped to a hypothetical protein (A0A0M4S069) reannotated as "Antifreeze protein" in $104 \mathrm{M}$. The "Antifreeze protein" has both a high Vaxilen score and MP3 score and is likely be involved in antigenicity and virulence (Additional file 1: Table S5). In summary, 218 hypothetical proteins of $B$. abortus $104 \mathrm{M}$ that were functionally uncharacterized in preliminary studies were confirmed at the protein level during this study. In addition, several of these hypothetical proteins were predicted to be "probable antigens" or "virulent proteins", which may have some influences on the bacterial virulence and vaccine protection. The conservation of the new virulence factors and protective antigens were assessed at both the nucleotide and predicted amino acid levels using the genome sequences of 18 different B. abortus strains [39]. Overall, these analyses demonstrate that thus the newly identified 
virulence factors, and protective antigens were well conserved among the analyzed isolates.

\section{Refinement of genome annotation by proteogenomic analysis}

All spectra were searched against the $6 \mathrm{~F}$ database. The detected peptides were further analyzed via the Visual Exploration and Statistics to Promote Annotation (VESPA) tool and were then mapped to the B. abortus 104 $\mathrm{M}$ genome [40]. Of these, 74 peptides were orphans that did not map to any annotation in the $104 \mathrm{M}$ genome (Additional file 1: Table S6). Based on our analysis, we identified six novel ORFs and modified three existing ORF models (Table 2). All of the corrections and identifications were assigned to at least two unique orphan peptides. Blast analysis of these novel annotation ORFs across related species revealed the presence of orthologous for all of the novel unannotated ORFs; the analysis also revealed errors in other B. abortus strains [41].

Among the novel ORFs identified, two unique peptides were mapped to a novel ORF (NZ_CP009625_3701) located in the intergenic region between two annotated ORFs (Additional file 2: Figure S3A). This novel ORF contains an Aldedh PFAM structural domain that shares high homology with the aldehyde dehydrogenase protein (A0A0M1WD82) in B. abortus [42]. Reverse transcriptionPCR (RT-PCR) analysis confirmed that this progenitor ORF is transcribed; suggesting that our identification of novel ORF models was reliable (Fig. 5a). We also identified some erroneously assigned ORF translation initiation sites (TIS). For example, four peptides were first observed to match the upstream region of an existing ORF (NZ_CP009626_26949) that has previously been shown to contain a VirJ PFAM structural domain (Additional file 2: Figure S3B). We found an additional 32 amino acids upstream of the protein start site compared with the annotated genome. Validation of these upstream regions by RT-PCR allowed us to annotate a new accurate start site (Fig. 5b). We analyzed protein TIS by probing N-terminal acetylation modification.
The modification directly marked the TIS of protein-coding genes [43]. Based on peptides identified at 1\% FDR, and their upstream codons, we confirmed the annotated TIS for 29 genes. List of N-terminal acetylation identified in this study are presented in Additional file 1: Table S7.

In this study, we integrated the B. abortus $104 \mathrm{M}$ proteomics information with genome annotation data to identify novel ORFs and validate existing modified ORF models. These observations showed that the identified protein coding genes of the $B$. abortus 104 M genome are well annotated with only six novel ORFs and three existing ORF model errors. Exploring the biological functions of these novel ORFs are under investigation. The refinement of $B$. abortus $104 \mathrm{M}$ genome annotation in this study improved its genome annotation quality. We also confirmed the annotated TIS for 29 genes through Nterminal acetylation analysis. Further research pertaining to N-terminal peptides from other internal digested peptides is required to identify $\mathrm{N}$-terminally modified peptides and gain more information about TISs in B. abortus.

\section{Differential protein expression between the two bacterial chromosomes}

B. abortus is a multichromosome bacterium, with the associated genome harboring two replicons of unequal sizes [44]. In B. abortus, the large chromosome (Chr I, $2.1 \mathrm{Mb}$ ) encodes for most of the house-keeping functions, while the small chromosome (Chr II, 1.2 Mb) contains genes mostly of unknown origin and function [45]. The protein expression from multipartite genomes has been poorly investigated. Protein expression and subsequent stability requires a series of linked processes including transcription, processing and degradation. Protein abundance reflects the dynamic balance of these processes and, therefore, may has a positive correlation with expression levels [46].

In general, an increase in protein abundance typically results in an increase in the number of proteolytic peptides, and vice versa. A resultant increase in the number of (tryptic) digests will usually result in an increase in

Table 2 The novel ORFs and annotation errors of B. abortus 104 M identified in this study

\begin{tabular}{lllll}
\hline Proteogenomic Analysis Group & Six-frame Accessions & Description & Protein Length & Identified Peptides \\
\hline Novel ORFs & NZ_CP009625_614 & 30S ribosomal protein S1 & 582 & 24 \\
& NZ_CP009625_3701 & Aldehyde dehydrogenase & 301 & 3 \\
& NZ_CP009625_52863 & Transporter & 287 & 2 \\
& NZ_CP009625_60998 & Hypothetical protein & 157 & 41 \\
& NZ_CP009625_73594 & Phosphoglucomutase & 568 & 2 \\
Annotation errors & NZ_CP009626_31772 & Glycerol-3-phosphate dehydrogenase & 218 & 3 \\
& NZ_CP009625_16344 & Peptide chain release factor 2 & 356 & 12 \\
& NZ_CP009626_15797 & Cytoplasmic protein & 247 & 16 \\
& NZ_CP009626_26949 & Virulence protein & 479 & 14 \\
\hline
\end{tabular}



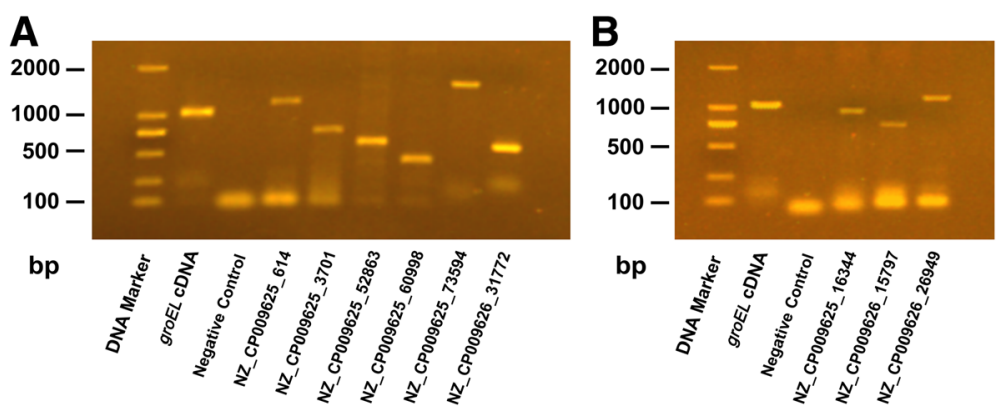

Fig. 5 Refinement of B. abortus $104 \mathrm{M}$ genome annotation validated by RT-PCR. a Novel ORF models and $\mathbf{b}$ annotation errors of B. abortus $104 \mathrm{M}$ were detected and validated at the transcriptional level by RT-PCR. For the PCR amplification: template, novel ORF models and errors CDNA; negative control, RNAs; positive control, groEL cDNA

protein sequence coverage, identified unique peptides, and identified total MS/MS spectra (spectral count) for each protein [47]. The protein abundance associated with 1,729 proteins relative to their chromosomal location in $B$. abortus $104 \mathrm{M}$ were analyzed using identified unique peptides and PSMs of each protein. The Wilcoxon-Rank-Sum test was applied to determine statistical significance. According to our results, the average identified peptide number and PSM number was higher for Chr I compared with Chr II (peptide number 14.03>11.81, Wilcoxon-Rank-
Sum test $p$-value $<0.01$; PSM number $128.9>101.6$, Wilcoxon-Rank-Sum test $p$-value $<0.01$, Fig. 6a).

Since larger proteins would be expected to generate more peptides and, therefore, more spectral counts than smaller proteins, we used normalized spectral abundance factors (NSAF) for comparison of relative quantitation [48]. The NSAF values for each detected protein are presented in Additional file 1: Table S2. After comparing protein abundance between the two chromosomes using the NSAF values, we observed that the relative abundance

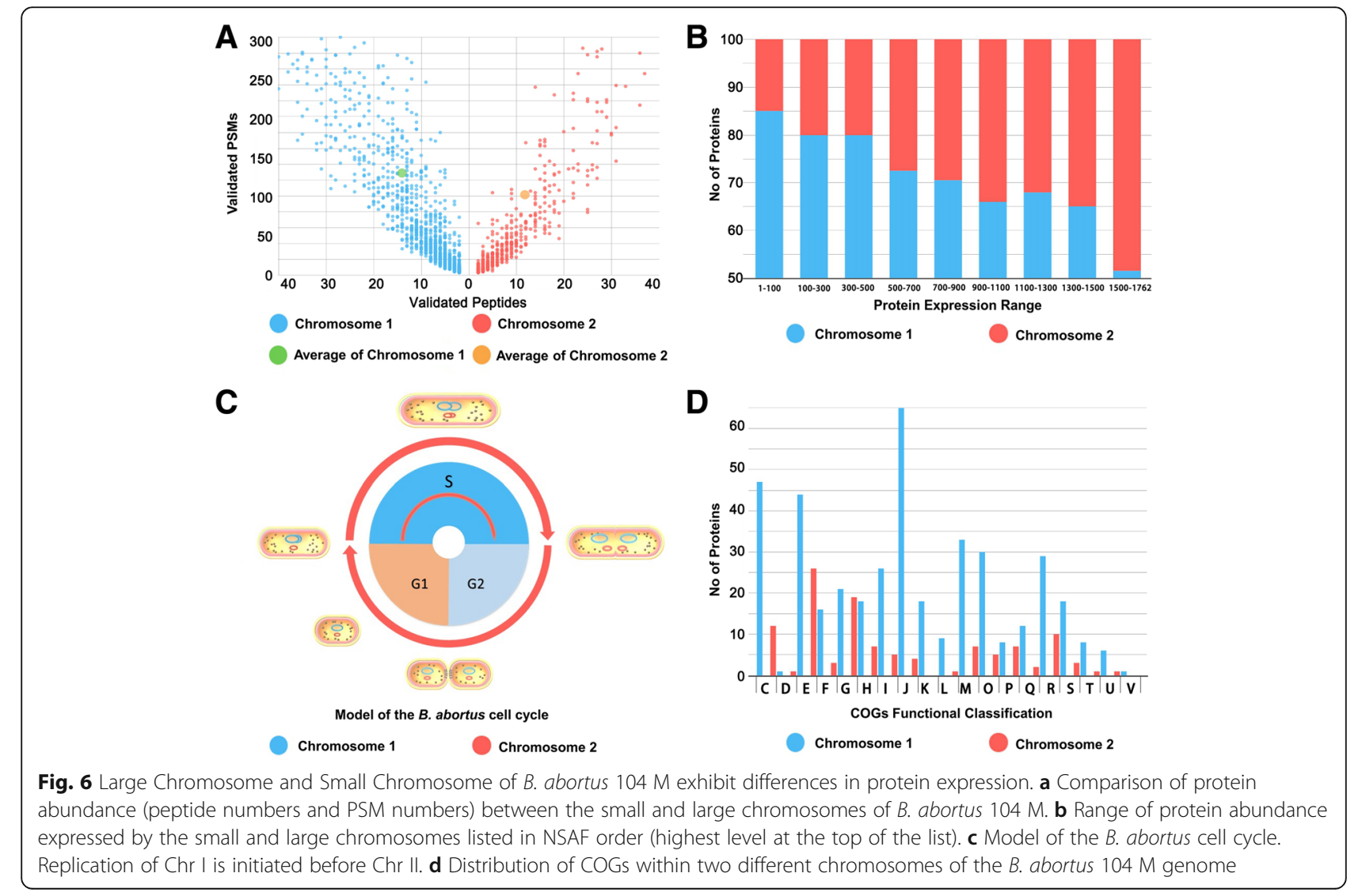


of proteins pertaining to Chr I was generally higher compared with Chr II $\left(6.364 \times 10^{-4}>4.38 \times 10^{-4}\right.$, Wilcoxon-Rank-Sum test $p$-value $<0.01)$. The differential protein abundance between the two chromosomes in $B$. abortus $104 \mathrm{M}$ was considered to be statistically significant, which may reflect the differential protein expression between the two bacterial chromosomes.

Proteins were ranked from highest to lowest according to the NSAF values (Fig. 6b). If the expression levels of proteins located on the large and small chromosomes are randomly distributed, then the expected ratio of Chr II proteins would be $1,071 / 3,072$ (or $34.9 \%$ ) in any arbitrarily selected range. However, according to our results, the actual proportions of Chr II proteins (505/1729, $29.2 \%)$ were lower than expected for the upper range of expression levels, except for those proteins with the highest expression levels. For example, of the proteins with expression levels ranging from 1 to 500 , only 95 proteins (19\%) were located on Chr II. The protein expression levels pertaining to Chr I were generally higher compared with Chr II.

It is well known that the replication of the B. abortus genome occurs concomitantly with cell growth and division. The origin and terminator regions of multichromosomes in $B$. abortus have distinct dynamics and localization patterns, whereby the large chromosome is replicated prior to the small chromosome (Fig. 6c) [45]. In addition, the replication of chromosomes results in an increase in the copy number of genes located near origins of replication compared with genes located near termini. This may be a potential reason for the differential protein expression between the large and small chromosome. Moreover, an analysis conducted to elucidate the COG categories of the 500 most highly expressed genes in B. abortus $104 \mathrm{M}$ suggests that the proteins associated with rapid cell growth are expressed at relatively high levels. The genes encoding for these proteins were overrepresented on the large chromosome and concurrently under-represented on the small chromosome (Fig. 6d).

We also analyzed the GC composition and codon usage between the two chromosomes in B. abortus that may affect translation or protein expression. The results showed that there was no significant difference in GCcontent $(57.2 \% / 57.3 \%)$ and codon usage between the two chromosomes (date shown in Additional file 1: Table S8) [7]. The potential reason for differential protein expression may be related to the replication dynamics and gene function differences of the two chromosomes in this multichromosomal bacterium. This study is the first to report differences in protein expression levels in two chromosomes in this multichromosomal bacterium and is in accordance with a similar pattern reported for Vibrio cholera following transcriptome analysis $[49,50]$.

\section{Conclusions}

Brucellosis is a significant economic and public health problem worldwide. The $B$. abortus $104 \mathrm{M}$ vaccine strain has played an important role in the prevention and control of brucellosis in China. In this study, we used a proteogenomics approach that combined subcellular fractionation and peptide fractionation to perform whole-proteome analysis and genome reannotation in B. abortus $104 \mathrm{M}$. In total, 1,729 proteins (56.3\% of 3072 ), including 218 hypothetical proteins, were identified under the culture conditions given in this study. As part of this analysis, 14 pivotal virulence factors, 17 known protective antigens and other important protein effectors that are related to bacterial virulence and vaccine protection were confirmed. These data represents a dataset of proteins identified following growth of $104 \mathrm{M}$ under conventional culture conditions. It is possible that some coding sequences did not express under the conditions chosen in this study. Analysis of differential proteome expression patterns of $B$. abortus in other culture conditions can serve as a starting point in the discovery of protein determinants associated with pathogen adaptation and pathogenesis. These differentially expressed genes potentially promote pathogen adaptation to more complex in vivo environments and, therefore, require further study.

In this study, we also validated the B. abortus $104 \mathrm{M}$ genome annotation and re-annotated mis-annotated ORFs; validation improved the quality of the genome annotation. Six novel ORFs and three modified existing ORFs were also identified as part of this study. We confirmed the annotated TIS for 29 genes through $\mathrm{N}$-terminal acetylation analysis. Furthermore, after comparing protein abundance using NSAF values, we observed differential protein expression between the two bacterial chromosomes in in $B$. abortus $104 \mathrm{M}$. The potential reason for this differential expression may be related to differences in the replication dynamics and gene function pertaining to the two chromosomes; further work is required to verify this hypothesis. In conclusion, this study represents a comprehensive proteogenomics analysis of $B$. abortus $104 \mathrm{M}$ and is likely to improve our understanding of the mechanisms that underpin residual toxicity and vaccine-induced immune protection.

\section{Methods}

\section{Cell culture and protein extraction}

The 104 M strain was grown in tryptic soy broth (TSB) and harvested in the early exponential phase. Whole cell protein samples were prepared as described previously with some modifications [11]. Briefly, cells harvested by centrifugation $\left(7,000 \times g, 15 \mathrm{~min}\right.$ at $\left.4{ }^{\circ} \mathrm{C}\right)$ were washed followed by resuspension in lysis buffer and disruption by ultra-sonication ( $25 \%$ amplitude, $15 \mathrm{~min}$ at $0{ }^{\circ} \mathrm{C}$ ). The resultant suspension was centrifuged $(40,000 \times g$, $30 \mathrm{~min}$ at $18{ }^{\circ} \mathrm{C}$ ) and the protein concentrations in the collected 
supernatants were measured using a BCA protein assay kit (Thermo Fischer Scientific, Waltham, USA).

Total membrane protein samples were also prepared using Triton X-114 phase-separation as described previously [51]. In brief, harvested cells were lysed by bead beating and then centrifuged $\left(7,000 \times g, 15 \mathrm{~min}\right.$ at $\left.4{ }^{\circ} \mathrm{C}\right)$ to remove insoluble material. Triton X-114 (2\% v/v concentration) was added to the supernatant and then stirred $\left(10 \mathrm{~min}\right.$ at $4{ }^{\circ} \mathrm{C}$ ) to obtain the protein extract in a single phase. This mixture was then centrifuged $(15,000 \times g$, $10 \mathrm{~min}$ at $4{ }^{\circ} \mathrm{C}$ ) to remove residual insoluble matter and incubated at $37{ }^{\circ} \mathrm{C}$ for $10 \mathrm{~min}$. Subsequently, the solution was separated into upper (aqueous) and lower (detergent) phases. The detergent phase was collected and proteins were precipitated by acetone. Protein samples were stored at $-80{ }^{\circ} \mathrm{C}$ for further analysis.

Protein pre-fractionation and in-gel proteolytic digestion Whole cell protein and membrane protein extracts were resolved by $12 \%$ SDS polyacrylamide gel electrophoresis, stained with Coomassie blue R250 and excised into gel slices, which were then subjected to an in-gel tryptic digestion protocol [51]. In brief, protein-containing lanes were excised from the gels based on molecular weight and local protein amount. Each band was placed into an Eppendorf tube and destained with 30\% acetonitrile and $35 \mathrm{mM}$ ammonium bicarbonate until colorless. Gel pieces were treated with pure acetonitrile and dried under vacuum. Sufficient ammonium bicarbonate (at a final concentration of $50 \mathrm{mM}$ ) was added to each tube to cover the gel pieces. Trypsin was subsequently added and the tubes were placed on ice for $40 \mathrm{~min}$. All tubes were then incubated at $37{ }^{\circ} \mathrm{C}$ for $12 \mathrm{~h}$ and centrifuged $(12,000 \times g$, $1 \mathrm{~min})$. Peptides were extracted from each supernatant as follows: $50 \mu \mathrm{l}$ extraction buffer (5\% formic acid, $50 \%$ acetonitrile) was added and the resultant mixture was centrifuged $(12,000 \times \mathrm{g}, 1 \mathrm{~min})$. Following incubation for $4 \mathrm{~min}$ at room temperature, all supernatants were collected into new tubes. Acetonitrile (100\%) was added to each tube and these mixtures were mixed by vortexing for $20 \mathrm{~min}$. Following centrifugation $(12,000 \times \mathrm{g}, 1 \mathrm{~min})$, the resultant mixtures were incubated for $4 \mathrm{~min}$ at room temperature; the supernatants were subsequently collected. The resultant peptides were dried under vacuum and stored at $-80{ }^{\circ} \mathrm{C}$ until further use.

\section{In-solution proteolytic digestion and peptide pre- fractionation}

Whole cell protein and membrane protein extracts were reduced $\left(20 \mathrm{~min}\right.$ at $25^{\circ} \mathrm{C}$ ) in $1 \mathrm{mM}$ dithiothreitol and then alkylated in $5.5 \mathrm{mM}$ iodoacetamide $\left(15 \mathrm{~min}\right.$ at $25^{\circ} \mathrm{C}$ in the dark) [52]. Trypsin was added (1:50, w/w) and proteins were digested in solution overnight before samples were separated by SCX performed on a Dionex UltiMate 3000
(Thermo Fischer Scientific). Tryptic peptides were loaded onto a PolySUlFOETHYL A (PolyLC, Columbia, MD, USA) column and eluted with a linear gradient using ACN/potassium phosphate buffers. After the elution, flow-through fractions were collected into fresh Eppendorf tubes. Adjacent fractions were desalted by $\mathrm{C} 18$ reversed-phase spin columns, separated into aliquots containing $150 \mu \mathrm{g}$ peptides, dried under vacuum and stored at $-80{ }^{\circ} \mathrm{C}$ until further use.

\section{LC-MS/MS analysis}

The nanoAcquity Ultra Performance LC system (Waters Corporation, Milford, USA) was used for peptide separation equipped with a C18 reversed-phase microcapillary trapping (Maisch, Ammerbuch-Entringen, Germany) as described previously [53]. A total of 90 samples (30 samples conducted in triplicate) were loaded and eluted for 40 min using a 5-40\% CAN fraction-optimized nonlinear gradient in $0.1 \%$ formic acid. Eluted peptides were analyzed using a LTQ Obitrap Velos mass spectrometer (Thermo Fisher Scientific) as previously described [51]. The eluted peptides were electrosprayed with a distally applied spray voltage of $2.0 \mathrm{kV}$. The mass spectrometry analysis was carried out in a data-dependent manner. Survey scans were performed at a resolution of 30,000 at target values of 1,000,000 ions in the Orbitrap analyzer with maximum allowed fill times of $150 \mathrm{~ms}$ over a mass range of $300-1,600 \mathrm{~m} / \mathrm{z}$. Finally, the 20 most intense precursor ions were chosen for MS/MS fragmentation by collision-induced fragmentation. The normalized collision energy for the MS/MS was set to $30 \%$, and the transfer tube temperature was maintained at $220^{\circ} \mathrm{C}$. Exclusion of precursor ion masses over a time window of $30 \mathrm{~s}$ was used to suppress repeated fragmentation of peaks.

\section{Database construction and data processing}

The protein database used for MS/MS searches was constructed from the UniProt entries for B. abortus $104 \mathrm{M}$ and comprised of 3,072 proteins. A six reading frame $(6 \mathrm{~F})$ database was constructed based on all six possible ORFs in the 104 M genome using the "getorf" program in EMBOSS, with all sequences between two stop codons regarded as a protein in this database [54]. The $6 \mathrm{~F}$ database comprised 115,420 candidate coding sequences for all of the possible proteins (longer than 20 amino acids) encoded by the genome. Peak lists obtained from MS/MS spectra were identified using X! Tandem, MS-GF+, Comet and PeptideShaker. The identification was conducted using SearchGUI [55-57]. The decoy sequences were created by reversing the $104 \mathrm{M}$ UniProt database. The Enzyme specificity was set to trypsin and a maximum of two missed cleavages were allowed. The initial maximal was set to $20.0 \mathrm{ppm}$ as MS1 and 0.5 Da as MS2 tolerances. The fixed modifications carbamidomethylation of $\mathrm{C}$, 
variable modifications oxidation of $\mathrm{M}$ and acetylation of protein $\mathrm{N}$-term were used. Protein identification was conducted against a concatenated target-decoy version of the B. abortus $104 \mathrm{M}$ complement of the UniProt database. PeptideShaker provides statistical confidence estimates for each peptide and protein, taking into account protein inference issues. PSMs, peptides, and proteins were validated at a 1.0\% FDR using the decoy hit distribution. All of the raw mass spectra files along with the identification results have been deposited into the ProteomeXchange Consortium via the PRIDE partner repository with the dataset identifier PXD005403 and are now available $[58,59]$.

\section{Bioinformatics tools for the prediction of proteins}

The analysis of unique proteins identified by different proteomics strategies was conducted using Patternlab4.0 [60]. The venn diagram and circular map of the genome were drawn using jvenn and Circos [61, 62]. The theoretical molecular mass and pI, and GRAVY values were predicted using the ExPASy-ProtParam tool [18]. Protein transmembrane helices were predicted using TMHMM 2.0 [19]. The subcellular localization was predicted using the Cello2.5 program [20]. The COGs classification system was employed to examine the distribution of different gene categories [21]. The protective antigens GO analyses were performed using the Blast2Go online tool [36]. The protective antigens probability scores were predicted using the VaxiJen2.0 server [37]. Antigens were specified as pathogenic or nonpathogenic by the MP3 server [38]. The conservation of new virulence factors and, protective antigens were assessed at both nucleotide and predicted amino acid levels between 18 different $B$. abortus strains, using ClustalOmega [63]. The pfam protein family database was used to generate a complete and accurate classification of protein families and domains [42]. All statistical analyses were performed using GraphPad Prism (GraphPad Software, La Jolla, CA, USA).

\section{Proteogenomic workflow and bioinformatics analysis}

All spectra were searched against the $6 \mathrm{~F}$ database [16]. The detected peptides (1\% FDR) and the B. abortus 104 $M$ genome with associated annotations were imported into the VESPA proteogenomic program [39]. Peptides were mapped to the $104 \mathrm{M}$ genome sequence and a set of unique peptides that did not match the annotated proteins of B. abortus 104 M (orphan peptides) were identified and then mapped to the unique locations on the 104 M genome. After the analysis, the annotations of existing ORF models were modified and novel ORFs were identified. All annotation identifications and corrections were assigned on the basis of at least two unique orphan peptides.

\section{RT-PCR validation}

The novel ORF models and errors identified in this study were validated at the transcriptional level by RTPCR as previously described [64]. The total RNA was extracted using the RNeasy Mini Kit (Qiagen, Valencia, CA) and then RNase-free DNase was added to remove any contaminating genomic DNA. The cDNA synthesis was performed using the QuantiTect Reverse Transcription Kit (Qiagen). For the PCR reaction, the novel ORF models and errors cDNA was used as a template, while RNA and groEL cDNA were used as negative and positive controls, respectively. The gene-specific primers in this study are listed in Additional file 1: Table S9.

\section{Additional files}

Additional file 1: This file contains supplementary Tables S1-S9. Table S1. The $6 \mathrm{~F}$ translated genome database of B. abortus $104 \mathrm{M}$ used in this study. Table S2. List of proteins identified in this study. Table S3. List of peptides identified in this study. Table S4. List of PSMs identified in this study. Table S5. List of hypothetical proteins identified in this study and function analysis. Table S6. List of orphan peptides identified in this study. Table S7. List of Nterminal acetylation identified in this study. Table S8. The codon usage of two chromosomes in B. abortus 104 M. Table S9. List of primers used for RTPCR amplifications in this study. (XLSX $38564 \mathrm{~kb}$ )

Additional file 2: This file contains supplementary Figures S1-S3. Figure S1. Summary of proteome analysis in this study. Figure S2. The unique proteins identified by different proteomics strategies in this study. Figure S3. Refinement of genome annotation by proteogenomic analysis in this study. (DOC $1842 \mathrm{~kb})$

\section{Abbreviations}

2-DE: Two dimensional gel electrophoresis; COG: Clusters of orthologous groups; FDR: False discovery rate; GO: Gene ontology; GRAVY: Grand average of hydropathy; HPLC: High performance liquid chromatography; LTQ: Linear trap quadrupole; MS: Mass spectrometry; MS/MS: Tandem mass spectrometry; MW: Molecular weights; NSAF: normalized spectral abundance factors; ORF: Open reading frame; PAGE: Polyacrylamide gel electrophoresis; pl: Isoelectric point; PSMs: Peptide spectrum matches; RT-PCR: Reverse transcription-PCR; SCX: Strong cation exchange; TIS: Translation initiation site; $\mathrm{TMH}$ : Transmembrane helix; TSB: Tryptic soy broth

\section{Acknowledgements}

We thank Hengliang Wang, Li Zhu and Zhiqi Gao at the Beijing Institute of Biotechnology for helpful discussions.

\section{Funding}

This work was financially supported by the National Science and Technology Major Project of China (2013ZX09304101 and 2016ZX10004001). The funders had no role in study design, data collection, interpretation, or decisionmaking in relation to submission for publication.

\section{Availability of data and materials}

All data generated or analyzed during this study are included in this published article and its additional files. The mass spectrometry proteomics data have been deposited to the ProteomeXchange Consortium (http:// proteomecentral.proteomexchange.org) via the PRIDE partner repository with the dataset identifier PXD005403.

\section{Authors' contributions}

$X Z$, JX, and WC conceived and designed the experiments; $X Z, Q Y, K L, R L$ and LF performed the experiments; $X Z, M Q$ and $Q Y$ analyzed the data; $Y L, T Z$, DD and $Y Y$ contributed to the reagents; and $X Z, S L$ and JX wrote the paper. All authors read and approved the finalized manuscript. The authors report no potential conflicts of interest. 


\section{Competing interests}

The authors declare that they have no competing interests.

\section{Consent for publication}

Not applicable.

Ethics approval and consent to participate

Not applicable.

\section{Publisher's Note}

Springer Nature remains neutral with regard to jurisdictional claims in published maps and institutional affiliations.

\section{Received: 21 November 2016 Accepted: 16 May 2017}

\section{Published online: 23 May 2017}

\section{References}

1. Olsen SC, Palmer MV. Advancement of knowledge of Brucella over the past 50 years. Vet Pathol. 2014;51(6):1076-89.

2. Atluri VL, Xavier MN, de Jong MF, den Hartigh AB, Tsolis RM. Interactions of the human pathogenic Brucella species with their hosts. Annu Rev Microbiol. 2011;65:523-54.

3. Doganay GD, Doganay M. Brucella as a potential agent of bioterrorism. Recent Pat Antiinfect Drug Discov. 2013;8(1):27-33.

4. Goodwin ZI, Pascual DW. Brucellosis vaccines for livestock. Vet Immunol Immunopathol. 2016. doi:10.1016/j.vetimm.2016.03.01.

5. Dorneles EM, Sriranganathan N, Lage AP. Recent advances in Brucella abortus vaccines. Vet Res. 2015;46:76.

6. Wang Y, Ke Y, Wang Z, Yuan X, Qiu Y, Zhen Q, et al. Genome sequences of three live attenuated vaccine strains of Brucella species and implications for pathogenesis and differential diagnosis. J Bacteriol. 2012;194(21):6012-3.

7. Yu D, Hui Y, Zai X, Xu J, Liang L, Wang B, et al. Comparative genomic analysis of Brucella abortus vaccine strain $104 \mathrm{M}$ reveals a set of candidate genes associated with its virulence attenuation. Virulence. 2015;6(8):745-54.

8. Uszkoreit J, Plohnke N, Rexroth S, Marcus K, Eisenacher M. The bacterial proteogenomic pipeline. BMC Genomics. 2014;15 Suppl 9:S19.

9. Sandalakis V, Psaroulaki A, De Bock PJ, Christidou A, Gevaert K, Tsiotis G, et al. Investigation of rifampicin resistance mechanisms in Brucella abortus using MSdriven comparative proteomics. J Proteome Res. 2012;11(4):2374-85.

10. Paredes-Cervantes V, Flores-Mejia R, Moreno-Lafont MC, Lanz-Mendoza $H$, Tello-Lopez AT, Castillo-Vera J, et al. Comparative proteome analysis of Brucella abortus 2308 and its virB type IV secretion system mutant reveals new T4SS-related candidate proteins. J Proteomics. 2011;74(12):2959-297.

11. Lamontagne J, Beland M, Forest A, Cote-Martin A, Nassif N, Tomaki F, et al. Proteomics-based confirmation of protein expression and correction of annotation errors in the Brucella abortus genome. BMC Genomics. 2010;11:300.

12. Al Dahouk S, Loisel-Meyer S, Scholz HC, Tomaso H, Kersten M, Harder A, et al. Proteomic analysis of Brucella suis under oxygen deficiency reveals flexibility in adaptive expression of various pathways. Proteomics. 2009;9(11): 3011-302

13. Eschenbrenner M, Horn TA, Wagner MA, Mujer CV, Miller-Scandle TL, DelVecchio VG. Comparative proteome analysis of laboratory grown Brucella abortus 2308 and Brucella melitensis 16 M. J Proteome Res. 2006;5(7):1731-40.

14. Wagner MA, Eschenbrenner M, Horn TA, Kraycer JA, Mujer CV, Hagius S, et al. Global analysis of the Brucella melitensis proteome: Identification of proteins expressed in laboratory-grown culture. Proteomics. 2002;2(8):1047-60.

15. Feist $\mathrm{P}$, Hummon AB. Proteomic challenges: sample preparation techniques for microgram-quantity protein analysis from biological samples. Int J Mol Sci. 2015;16(2):3537-63.

16. Pendarvis K, Padula MP, Tacchi JL, Petersen AC, Djordjevic SP, Burgess SC, et al. Proteogenomic mapping of Mycoplasma hyopneumoniae virulent strain 232. BMC Genomics. 2014;15:576.

17. Apweiler R, Bairoch A, Wu CH. Protein sequence databases. Curr Opin Chem Biol. 2004;8(1):76-80

18. Gasteiger E, Gattiker A, Hoogland C, Ivanyi I, Appel RD, Bairoch A. ExPASy: the proteomics server for in-depth protein knowledge and analysis. Nucleic Acids Res. 2003:31(13):3784-8.

19. Krogh A, Larsson B, von Heijne G, Sonnhammer EL. Predicting transmembrane protein topology with a hidden Markov model: application to complete genomes. J Mol Biol. 2001;305(3):567-80.
20. Shi JY, Zhang SW, Pan Q, Cheng YM, Xie J. Prediction of protein subcellular localization by support vector machines using multi-scale energy and pseudo amino acid composition. Amino Acids. 2007;33(1):69-74.

21. Tatusov RL, Koonin EV, Lipman DJ. A genomic perspective on protein families. Science. 1997;278(5338):631-7.

22. Delrue RM, Lestrate P, Tibor A, Letesson JJ, De Bolle X. Brucella pathogenesis, genes identified from random large-scale screens. FEMS Microbiol Lett. 2004;231(1):1-12.

23. Elfaki MG, Alaidan AA, Al-Hokail AA. Host response to Brucella infection: review and future perspective. J Infect Dev Ctries. 2015;9(7):697-70.

24. Chen L, Yang J, Yu J, Yao Z, Sun L, Shen Y, et al. VFDB: a reference database for bacterial virulence factors. Nucleic Acids Res. 2005;33(Database issue):D325-8.

25. Arellano-Reynoso B, Lapaque N, Salcedo S, Briones G, Ciocchini AE, Ugalde $R$, et al. Cyclic beta-1,2-glucan is a Brucella virulence factor required for intracellular survival. Nat Immunol. 2005:6(6):618-25.

26. Cardoso PG, Macedo GC, Azevedo V, Oliveira SC. Brucella spp noncanonical LPS: structure, biosynthesis, and interaction with host immune system. Microb Cell Fact. 2006;5:13

27. Lamontagne J, Butler H, Chaves-Olarte E, Hunter J, Schirm M, Paquet C, et al. Extensive cell envelope modulation is associated with virulence in Brucella abortus. J Proteome Res. 2007:6(4):1519-29.

28. de Jong MF, Tsolis RM. Brucellosis and type IV secretion. Future Microbiol. 2012:7(1):47-58.

29. Yang B, Sayers S, Xiang Z, He Y. Protegen: a web-based protective antigen database and analysis system. Nucleic Acids Res. 2011;39(Database issue): D1073-8.

30. He Y, Xiang Z. Bioinformatics analysis of Brucella vaccines and vaccine targets using VIOLIN. Immunome Res. 2010;6 Suppl 1:S5.

31. Ghasemi A, Jeddi-Tehrani M, Mautner J, Salari MH, Zarnani AH. Immunization of mice with a novel recombinant molecular chaperon confers protection against Brucella melitensis infection. Vaccine. 2014;32(49): 6659-66.

32. Singh $D$, Goel $D$, Bhatnagar R. Recombinant $L 7 / L 12$ protein entrapping PLGA (poly lactide-co-glycolide) micro particles protect BALB/c mice against the virulent B. abortus 544 infection. Vaccine. 2015;33(24):2786-92.

33. Kaur G, Singh S, Sunil Kumar BV, Mahajan K, Verma R. Characterization and immunogenicity of outer membrane vesicles from Brucella abortus. J Immunoassay Immunochem. 2016:37(3):261-72.

34. Tadepalli G, Singh AK, Balakrishna K, Murali HS, Batra HV. Immunogenicity and protective efficacy of Brucella abortus recombinant protein cocktail (rOmp19 + rP39) against B. abortus 544 and B. melitensis 16 M infection in murine model. Mol Immunol. 2016;71:34-4.

35. Ghasemi A, Jeddi-Tehrani M, Mautner J, Salari MH, Zarnani AH. Simultaneous immunization of mice with Omp31 and TF provides protection against Brucella melitensis infection. Vaccine. 2015.

36. Conesa A, Gotz S, Garcia-Gomez JM, Terol J, Talon M, Robles M. Blast2GO: a universal tool for annotation, visualization and analysis in functional genomics research. Bioinformatics. 2005;21(18):3674-6.

37. Doytchinova IA, Flower DR. VaxiJen: a server for prediction of protective antigens, tumour antigens and subunit vaccines. BMC Bioinformatics. 2007:8:4.

38. Gupta A, Kapil R, Dhakan DB, Sharma VK. MP3: a software tool for the prediction of pathogenic proteins in genomic and metagenomic data. PLoS One. 2014;9(4), e93907.

39. Xiang Z, Zheng W, He Y. BBP: Brucella genome annotation with literature mining and curation. BMC Bioinformatics. 2006;7:347.

40. Peterson ES, McCue LA, Schrimpe-Rutledge AC, Jensen JL, Walker H, Kobold $M A$, et al. VESPA: software to facilitate genomic annotation of prokaryotic organisms through integration of proteomic and transcriptomic data. BMC Genomics. 2012;13:13.

41. Camacho C, Coulouris G, Avagyan V, Ma N, Papadopoulos J, Bealer K, et al. BLAST+: architecture and applications. BMC Bioinformatics. 2009;10:42.

42. Finn RD, Coggill P, Eberhardt RY, Eddy SR, Mistry J, Mitchell AL, et al. The Pfam protein families database: towards a more sustainable future. Nucleic Acids Res. 2016;44(D1):D279-85.

43. Kumar D, Yadav AK, Kadimi PK, Nagaraj SH, Grimmond SM, Dash D. Proteogenomic analysis of Bradyrhizobium japonicum USDA110 using GenoSuite, an automated multi-algorithmic pipeline. Mol Cell Proteomics. 2013;12(11):3388-97.

44. Jha JK, Baek JH, Venkova-Canova T, Chattoraj DK. Chromosome dynamics in multichromosome bacteria. Biochim Biophys Acta. 2012;1819(7):826-9. 
45. De Bolle X, Crosson S, Matroule JY, Letesson JJ. Brucella abortus cell cycle and infection are coordinated. Trends Microbiol. 2015;23(12):812-82

46. Lu P, Vogel C, Wang R, Yao X, Marcotte EM. Absolute protein expression profiling estimates the relative contributions of transcriptional and translational regulation. Nat Biotechnol. 2007;25(1):117-24.

47. Washburn MP, Wolters $D$, Yates 3rd JR. Large-scale analysis of the yeast proteome by multidimensional protein identification technology. Nat Biotechnol. 2001;19(3):242-7.

48. Paoletti AC, Parmely TJ, Tomomori-Sato C, Sato S, Zhu D, Conaway RC, et al. Quantitative proteomic analysis of distinct mammalian Mediator complexes using normalized spectral abundance factors. Proc Natl Acad Sci U S A. 2006;103(50):18928-33.

49. Dryselius R, Izutsu K, Honda T, lida T. Differential replication dynamics for large and small Vibrio chromosomes affect gene dosage, expression and location. BMC Genomics. 2008:9:559.

50. Xu Q, Dziejman M, Mekalanos JJ. Determination of the transcriptome of Vibrio cholerae during intraintestinal growth and midexponential phase in vitro. Proc Natl Acad Sci U S A. 2003;100(3):1286-129.

51. Malen H, Pathak S, Softeland T, de Souza GA, Wiker HG. Definition of novel cell envelope associated proteins in Triton X-114 extracts of Mycobacterium tuberculosis H37Rv. BMC Microbiol. 2010;10:132.

52. Gao Z, Wang Z, Zhang K, Li Y, Zhang T, Wang D, et al. Experimental validation of Bacillus anthracis A16R proteogenomics. Sci Rep. 2015;5:14608.

53. Yang MK, Yang YH, Chen Z, Zhang J, Lin Y, Wang Y, et al. Proteogenomic analysis and global discovery of posttranslational modifications in prokaryotes. Proc Natl Acad Sci U S A. 2014;111(52):E5633-42.

54. Rice P, Longden I, Bleasby A. EMBOSS: the European Molecular Biology Open Software Suite. Trends Genet. 2000;16(6):276-7.

55. Vaudel M, Burkhart JM, Zahedi RP, Oveland E, Berven FS, Sickmann A, et al. PeptideShaker enables reanalysis of MS-derived proteomics data sets. Nat Biotechnol. 2015;33(1):22-4.

56. Vaudel M, Barsnes H, Berven FS, Sickmann A, Martens L. SearchGUI: an open-source graphical user interface for simultaneous OMSSA and X!Tandem searches. Proteomics. 2011;11(5):996-9.

57. Kim S, Pevzner PA. MS-GF+ makes progress towards a universal database search tool for proteomics. Nat Commun. 2014;5:5277.

58. Vizcaino JA, Deutsch EW, Wang R, Csordas A, Reisinger F, Rios D, et al. ProteomeXchange provides globally coordinated proteomics data submission and dissemination. Nat Biotechnol. 2014;32(3):223-6.

59. Vizcaino JA, Csordas A, Del-Toro N, Dianes JA, Griss J, Lavidas I, et al. 2016 update of the PRIDE database and its related tools. Nucleic Acids Res. 2016; 44(D1):D447-56.

60. Carvalho PC, Lima DB, Leprevost FV, Santos MD, Fischer JS, Aquino PF, et al. Integrated analysis of shotgun proteomic data with PatternLab for proteomics 4.0. Nat Protoc. 2016;1 1(1):102-17.

61. Bardou P, Mariette J, Escudie F, Djemiel C, Klopp C. jvenn: an interactive Venn diagram viewer. BMC Bioinformatics. 2014;15:293.

62. Krzywinski M, Schein J, Birol I, Connors J, Gascoyne R, Horsman D, et al. Circos: an information aesthetic for comparative genomics. Genome Res. 2009:19(9):1639-45.

63. Sievers F, Wilm A, Dineen D, Gibson TJ, Karplus K, Li W, et al. Fast, scalable generation of high-quality protein multiple sequence alignments using Clustal Omega. Mol Syst Biol. 2011;7:539.

64. Zheng J, Ren X, Wei C, Yang J, Hu Y, Liu L, et al. Analysis of the secretome and identification of novel constituents from culture filtrate of bacillus Calmette-Guerin using high-resolution mass spectrometry. Mol Cell Proteomics. 2013:12(8):2081-95.

\section{Submit your next manuscript to BioMed Central and we will help you at every step:}

- We accept pre-submission inquiries

- Our selector tool helps you to find the most relevant journal

- We provide round the clock customer support

- Convenient online submission

- Thorough peer review

- Inclusion in PubMed and all major indexing services

- Maximum visibility for your research

Submit your manuscript at www.biomedcentral.com/submit

) Biomed Central 